\title{
SERGUEI NO MÉXICO: GREENAWAY E A REPRESENTAÇÃO PÓS-MODERNA DO ARTISTA QUEER
}

\author{
Andrei dos Santos Cunha* \\ Universidade Federal do Rio Grande do Sul \\ Porto Alegre, RS \\ Elaine Barros Indrusiak ${ }^{* *}$ \\ Universidade Federal do Rio Grande do Sul \\ Porto Alegre, RS
}

\begin{abstract}
Resumo
Em seu filme Que viva Eisenstein! (2016), o diretor britânico Peter Greenaway homenageia a figura de um importante pioneiro da linguagem cinematográfica, Serguei Eisenstein, centrando a narrativa na passagem do cineasta soviético pelo México. O filme traz uma reflexão sobre as opções estéticas do próprio Greenaway, que, ao longo de sua carreira, em seu uso de intermídia, busca expandir o repertório da "montagem ideogramática" proposta por Eisenstein. $\mathrm{O}$ biopic se consolidou ao longo do tempo como um gênero que permitia a domesticação da figura do artista ou autor e a representação do processo criativo como um ato de purgação do corpo criador. Greenaway subverte as expectativas relacionadas ao gênero biopic, ao representar o artista de maneira não realista, e ao associar a identidade queer e o corpo de Eisenstein ao seu processo de pesquisa sensorial e de elaboração estética.
\end{abstract}

Palavras-chave: Eisenstein; Greenaway; Biopic; Intermídia; Identidades Queer

\section{EISENSTEIN IN MEXICO: GREENAWAY'S POST-MODERN REPRESENTATION OF THE QUEER ARTIST}

\begin{abstract}
In his film Eisenstein in Guanajuato (2016), British director Peter Greenaway pays homage to Soviet filmmaker Sergei Eisenstein, a pioneer who helped to create the language of film. The biopic focuses on Eisenstein's stay in Mexico. The film is also a meditation on Greenaway's own aesthetic choices. Throughout his career, Greenaway has made extensive use of intermedia, expanding the vocabulary of "ideogrammic montage", a theory of film editing first proposed by Eisenstein himself. The biopic, as a genre, became over time a platform that allows for the domestication of the figure of the artist or author and for the representation of the creative process as a purging act of the creative body. Greenaway subverts expectations regarding the biopic genre by shunning realism when representing the artist and by associating a queer identity and Eisenstein's body to the artist's processes of sensorial exploration and aesthetic development.
\end{abstract}

Keywords: Eisenstein; Greenaway; Biopic; Intermedia; Queer Identities

\footnotetext{
* Professor do Departamento de Línguas Modernas da Universidade Federal do Rio Grande do Sul. Doutor em Literatura Comparada pelo Programa de PósGraduação do Instituto de Letras da Universidade Federal do Rio Grande do Sul. E-mail: andreicunha@gmail.com

${ }^{* *}$ Professora do Departamento de Línguas Modernas e do Programa de Pós-Graduação em Letras da Universidade Federal do Rio Grande do Sul. Doutora em Literatura Comparada pela Universidade Federal do Rio Grande do Sul. E-mail: elaine.indrusiak@ufrgs.br
} 


\section{O corpo queer como campo de batalha ideológico}

Tradicionalmente, a relação entre figura heroica, nação e heteronormatividade é considerada como fundamental e defendida ferrenhamente no plano da representação simbólica. Quando o "herói” ganha elementos de uma identidade queer no biópico, encontramos muitas vezes grupos conservadores que reagem contra esse reframing. Assim, por exemplo, quando Oliver Stone sugeriu, em Alexandre (2004), uma ligação homoafetiva entre o conquistador macedônio e seu general, Heféstion, o filme sofreu ameaças de um advogado grego, que posteriormente se absteve de processar a produtora cinematográfica (GREEK, 2004). O filme Mishima - uma vida em quatro capitulos retrata em detalhes o melodramático suicídio do polêmico escritor, mas a representação de sua homossexualidade foi combatida por sua família, que obteve judicialmente a proibição de que o filme seja exibido no Japão. No Brasil, a "masculinidade tradicional" da figura mítica de Lampião também foi defendida na justiça (APÓS, 2014).

Analogamente, não são poucos os críticos e espectadores que prefeririam atribuir as escolhas temáticas de Que viva Eisenstein! (2016) à preferência peculiar de seu diretor, Peter Greenaway, pelo impactante, pelo sexual e pelo escatológico. Por outro lado, a obra talvez revele mais acerca do personagem histórico do que os relatos altamente controlados e censurados que compõem o discurso mais aceito, convenientemente distorcido de forma a se encaixar e reforçar a heteronormatividade de narrativas como a Mãe Rússia, a Revolução Soviética, o comunismo, as vanguardas cinematográficas ou mesmo a noção de fidelidade histórica.

Durante toda a sua carreira, Eisenstein teve de se manter "no armário", mas "quando se encontrava em períodos desfavoráveis de sua relação com a burocracia, começavam os sussurros" relacionados à sua homossexualidade (WAUGH, 1977, p.15). Após a sua morte, o Eisenstein profissional de cinema deu lugar ao mito cultural, e os historiadores se encarregaram de apagar de forma ainda mais eficaz os traços de sua identidade queer, que só começou a ser reavaliada ao final dos anos 1970 e até hoje é contestada ou escamoteada em contex- tos oficiais. O elemento homoerótico de sua estética, no entanto, é difícil de se ignorar:

Todos os seus personagens masculinos são heróis idealizados eroticamente com grande imediatez e apelo - em especial, as figuras da classe trabalhadora que tanto a história como a convicção pessoal determinaram que seriam os protagonistas de seus filmes. A questão vai além de um suposto "olho para a beleza humana, e em especial para a beleza masculina" [...]. A beleza física do herói proletário veio de uma confluência única de sensibilidade erótica e ideais políticos. (WAUGH, 1977, p.17)

Não se deve esquecer que as filmagens de Que viva Eisenstein! tiveram por contexto histórico uma fase de recrudescimento da homofobia de Estado na Rússia, tal como evidenciada pela aprovação em 2013 de uma "lei anti-propaganda gay" (RUSSIA, 2013). A disputa entre Greenaway e os guardiães da memória de Eisenstein adquire às vezes contornos de uma literal luta pela posse e pelo uso da imagem:

O filme de Greenaway intitulado Que viva Eisenstein! [...] foi inicialmente bem recebido na Rússia, cujo governo é proprietário de grande parte do acervo audiovisual necessário para a realização do projeto. No entanto, após análise do roteiro, a Agência de Cinema da Rússia manifestou desacordo com relação a alguns aspectos da história - como, por exemplo, as referências à homossexualidade de Eisenstein. Que Greenaway modificasse o roteiro, sugeriu a Agência, e então se falaria em cessão de imagens do acervo. (EISENSTEIN, 2015, p.10)

Assim, ao representar a identidade queer de Eisenstein, Greenaway fomenta uma discussão sobre os traços homoeróticos de sua formidável herança cultural, traços esses que Eisenstein corajosamente inseriu em suas obras sob terríveis riscos pessoais e que, até recentemente, eram ignorados ou subvalorizados. Nesse aspecto, Greenaway abraça uma tendência identificada por Julianne Pidduck em biopics contemporâneos, a de "explorar os aspectos psicossexuais de figuras históricas em vez de seus feitos políticos e artísticos" (2004, p.157). Tal tendência dá margem a um curioso para- 
doxo: por um lado, agrada ao conservadorismo, pois defende o resgate e a representação de "verdades históricas"; por outro, no entanto, desagrada a esse mesmo segmento, ao se valer da maior liberdade de expressão hoje conferida a minorias sexuais para revelar vozes e fatos tradicionalmente silenciados pela homofobia e as normas do patriarcado. Um caso exemplar dessa corrente é De-Lovely (Irwin Winkler, 2004), biopic que retoma a vida do compositor Cole Porter. Quaisquer falhas que possam ser identificadas na representação de Porter por Winkler são infinitamente mais defensáveis do que o retrato anteriormente apresentado em Night and Day (Michael Curtiz, 1946), uma narrativa que mantinha o compositor firmemente escondido no armário de celuloide.

Greenaway se lança em conjecturas semificcionais acerca das atividades sexuais e das desventuras amorosas de Eisenstein no México não por qualquer inclinação ao melodrama, mas por identificar ali o cerne da transformação que o diretor soviético brilhantemente projetou em seus filmes após o retorno à União Soviética. Ainda que tal opção reforce uma visão do mexicano como o exótico e sedutor, representação paradigmática - e problemática - dos povos latinos, a ficção de Greenaway ecoa passagens de textos autobiográficos e epistolares de Eisenstein aos quais pouca ou nenhuma atenção havia sido dada, a fim de não se "manchar a reputação" de um patrimônio nacional de uma Rússia ainda oficial e institucionalmente homofóbica.

Esse é o pano de fundo por trás do lançamento e da recepção de Que viva Eisenstein!. Segundo Michael O'Sullivan (2016), a intenção de Greenaway seria especular quanto aos motivos que fizeram com que os filmes dirigidos por Eisenstein na década de 1920 ( $A$ Greve, Encouraçado Potemkin e Outubro) resultassem tão distintos das obras produzidas após o período de suas viagens internacionais - em especial, Alexandre Nevsky (1938) e as duas partes de Ivan, o Terrível (1945 e 1958). Embora reconheça a riqueza formal dos filmes de ambas as fases, Greenaway vê, nos dois mais recentes, "mais empatia e maturidade emocional" do que nas obras anteriores (O'SULLIVAN, 2016). Explorando vários relatos já publicados acerca da homossexualidade de Eisenstein, o filme de Greenaway sugere que a transformação por que passou o diretor soviético teria ocorrido pela "confrontação com Eros e Thanatos" no México, durante as filmagens de Que viva México!, obra que ele nunca finalizou. Apropriando-se do subtítulo internacionalmente atribuído a Outubro ("dez dias que abalaram o mundo"), ${ }^{1}$ Greenaway oferece sua visão dos "dez dias que abalaram Eisenstein" (GREENAWAY, 2014).

A hipótese de Greenaway tem base em alguns relatos biográficos e mesmo em estudos críticos da obra de Eisenstein. Masha Salazkina, por exemplo, afirma que Eisenstein utilizava o termo "conflito bissexual" para designar "o melhor objeto de observação e principal forma de realização da experiência dialética no nível subjetivo" (SALAZKINA, 2009, p.127-128). Em uma carta à sua secretária (que viria posteriormente a ser sua esposa) Pera Atasheva,

[Eisenstein] anuncia estar apaixonado, e que ele finalmente fora capaz de "chegar às vias de fato" em uma relação sexual. O objeto do amor de Eisenstein era um homem de Guadalajara, Jorge Palomino y Cañedo. [...] Os detalhes do que realmente aconteceu nos encontros sexuais de Eisenstein são menos importantes do que o efeito que esses encontros tiveram sobre a maneira como Eisenstein teorizava suas experiências [...], fornecendo uma chave para compreendermos o conjunto de alusões sexuais e homoeróticas encontradas em suas obras artísticas e nos textos de sua autoria. (SALAZKINA, 2009, p.130)

A maneira como Greenaway resolve esse elemento biográfico em termos audiovisuais, no entanto, subverte as convenções do gênero biopic, dando preferência para a representação alegórica de questões ligadas ao corpo, à mortalidade e às nações. Uma cena é central a essa narrativa carnavalesca:

[Após uma visita guiada pela cidade, de volta ao] quarto de hotel do cineasta, Cañedo toma o papel de outro tipo de guia, fazendo escorrer óleo de oliva pelas costas de Eisenstein, enquanto dá um discurso sobre o Velho Mundo, o Novo Mundo, a história da sífilis, e a transmigração. Sorrindo, Eisenstein recebe então o manto metafórico, associando orgulhosamente 
a perda de sua virgindade à revolução ocorrida em seu país. Comparada a outras cenas de sexo gay do cinema, esta parece estabelecer o seu próprio marco de referência: ela é ao mesmo tempo sedutora, séria, absurda, engraçada, e, para Greenaway, algo como um triunfo gráfico. (ABELE, 2016)

A cena do defloramento de Eisenstein no filme de Greenaway dialoga com a história da representação do ato sexual no cinema. O óleo de oliva, referência tanto à latinidad de Cañedo ${ }^{2}$ como à Antiguidade grega, pode ser visto como também em diálogo com a cena do estupro de O Último Tango em Paris (a célebre "cena da manteiga"). Greenaway inverte, no entanto, a polaridade dos elementos presentes no filme de Bertolucci. A troca da manteiga por azeite de oliva estabelece uma interessante oposição entre culturas do "norte" (a França, a Rússia, os Estados Unidos) e as do "sul" (a Grécia, as culturas latinas e mediterrâneas, o México). O par manteiga/azeite pode também ser visto como uma diferenciação entre o sexo prosaico, heteronormativo, inserido em um marco de dominação e opressão, e o sexo queer, liberador, revelador. O sexo entre Eisenstein e Cañedo é também encenado como uma subjugação, mas, ao contrário do estupro e da violência que encontramos em $O$ Último Tango, existe aqui uma representação dialética do ato sexual, que, quando consensual, pode tanto transformar a submissão em dominação como a derrota em triunfo. $\mathrm{O}$ final da cena, ao associar o corpo de Eisenstein ao solo russo, dominado pela revolução e trespassado pela bandeira vermelha, pode sugerir que a entrega sexual é, dialeticamente, tanto uma forma de dissolução dionisíaca como uma espécie de ascese apolínea.

\section{Biópico: gênero, consolidação e ruptura}

O choque que uma cena de sexo (quase) explícito pode causar quando inserida no contexto de um biopic se deve em parte à história de consolidação desse gênero. Biografias sempre constituíram um tipo problemático de texto, mesmo antes de o pós-modernismo chamar atenção para a natureza essencialmente narrativa (e parcial) do discurso histórico. Embora o cinema conte com recursos mais "fidedignos" do que a mera verbalização para fins de representação de eventos passados (especialmente quando uma criteriosa pesquisa embasa a produção de um filme histórico ou biográfico), não existe motivo algum para se supor que as mesmas limitações e parcialidades intrínsecas às biografias escritas deixem de acometer as biografias filmadas, uma vez que "toda história escrita é produto de processos de condensação, deslocamento, simbolização e qualificação exatamente idênticos àqueles empregados na produção de representações filmadas" (WHITE, 1988, p.1194).

Entretanto, diferentemente das obras literárias, até pouco tempo atrás pairava sobre o que se convencionou chamar de biopics a pecha de "gênero de reputação duvidosa" (BINGHAM, 2010), a despeito da enorme popularidade e do grande impacto que produções biográficas costumam ter, por exemplo, na indústria cinematográfica dos Estados Unidos, onde, segundo Richard Corliss (2015), a elite do cinema premia abundantemente os filmes desse gênero, como uma espécie de "purgação", para que se sintam "cidadãos decentes". Embora produzidos em todo o mundo, os filmes biográficos sempre foram particularmente populares nos estúdios hollywoodianos e, durante a era do studio system (1920-1960), se notabilizaram não apenas pelas narrativas formulaicas, mas também pelo limitado escopo de representação - uma reduzida galeria de "tipos humanos" merecedores de biografias filmadas, como aponta George Custen (1992) em seu seminal estudo acerca do gênero. Como boa parte da produção hollywoodiana desse período, tais obras não se pautavam pelo experimentalismo estético, pela reflexão ideológica ou, tampouco, pela precisão histórica, visando apenas entreter e, evidentemente, alimentar o culto de celebridades e de valores que, a um só tempo, reforçavam paradigmas vigentes e estimulavam o consumo, de forma semelhante àquela apontada por Leo Lowenthal em seu estudo de biografias em revistas populares, onde esse gênero textual se limitaria a repetir "o que sempre soubemos" (2004, p.203).

A decadência do studio system, quando os produtores deixaram de ser os detentores absolutos das obras cinematográficas, bem como a emergência da televisão como meio de comunicação de massa preferencial da propaganda político-cultural-ideológica, conferiram maior liberdade ao cinema norte-americano no que tan- 
ge o tratamento dado às biografias. Segundo Bingham (2010, p.18), a partir de então, o gênero outrora "engessado" pelos padrões clássicos do melodrama passou à fase realista ("warts-and-all"); posteriormente, deu vazão às idiossincrasias autorais; em seguida, mudou seu foco para a investigação crítica, fase seguida pela da paródia. Mais recentemente, os biopics passaram a enfocar e desestigmatizar minorias e, desde 2000, ingressaram em uma fase "neoclássica", que aglutina elementos das fases anteriores.

Essa evolução do gênero em solo norte-americano atesta sua maturidade e, embora não tenhamos evidências de que os filmes biográficos de outras indústrias cinematográficas tenham experimentado as mesmas transições, a forte penetração do cinema hollywoodiano na maioria dos sistemas culturais atuais acarreta profunda influência na percepção dos paradigmas que orientam a representação biográfica e histórica no cinema (por assim dizer, a "recepção do público e da crítica"). Nesse sentido, estudos restritos ao universo hollywoodiano podem oferecer insights úteis à investigação de filmes estrangeiros, ainda que tais aplicações devam ser cuidadosamente refletidas.

Ao examinarmos a criteriosa pesquisa de Custen (1992), por exemplo, constatamos que mais de 35\% dos filmes biográficos lançados pelos grandes estúdios norte-americanos de 1927 a 1960 debruçaram-se sobre as vidas de artistas. ${ }^{3}$ Ainda que faltem dados sistematizados referentes a produções fora do contexto hollywoodiano, pode-se apontar diversos títulos produzidos em outros países no mesmo período e que se enquadram nessa mesma subcategoria, tais como A Infância de Gorki (União Soviética, 1938), Rembrandt (Reino Unido, 1936), Os Amantes de Montparnasse (produção ítalo-francesa acerca da vida de Modigliani, 1958), dentre outros. Apesar da grande quantidade de produções lançadas nessa época, muitos dos biopics do período "clássico" se notabilizaram por administrar exemplarmente o paradoxo de "declarar que cada vida - e cada filme sobre uma vida - era única dentro dos limites de um sistema de produção que se assegurava de que todos os produtos, e vidas, parecessem uns com os outros" (CUSTEN, 1992, p.148). A despeito da evolução do gênero, certos paradigmas se mantiveram, particu- larmente no tratamento dado ao diferencial da classe artística e à genialidade, usualmente contraposta a certo desajuste social e largamente associada a uma visão romântica e biografista da criação artística (VIDAL, 2007, p.7). Julie Codell identifica ainda outra prática recorrente em tais biografias:

Desde o Rembrandt de Alexander Korda (1936), os biopics têm apagado, exagerado ou inventado conteúdo biográfico, de forma a naturalizar a abjeção como essencial ao caráter do artista e definir a função do artista como bode expiatório cultural. As mortes de artistas são um estágio necessário no processo de purificação, tornando a arte transcendente $\mathrm{e}$ "atemporal", ao libertá-la de corpos e histórias. [...] O corpo abjeto do artista deve ser sacrificado ao corpo da arte em uma luta pelo poder fálico. (CODELL, 2014, p.160)

Em 1966, produzindo sob um regime comunista ainda não suficientemente desestalinizado a ponto de permitir críticas veladas, Andrei Tarkovsky finalizaria Andrei Rublev, obra baseada na vida do iconografista medieval epônimo, santo da igreja ortodoxa e herói nacional russo que, curiosa e paradoxalmente, "não pinta ou faz qualquer coisa heroica" (ROSE, 2010) ao longo dos 205 minutos da narrativa. Destoando da convenção de se enfocar o artista pelo prisma de sua produção artística, Andrei Rublev apresenta uma visão bem mais complexa e psicologicamente apurada da construção e consumação do artista. A crise criativa do protagonista não representa apenas uma fase a ser superada, mas um fato tão formador quanto todos os momentos de exercício do ofício. A vida do artista não é sua obra: a obra resulta do somatório das experiências de vida, não porque tais experiências estejam, necessariamente, ali representadas ou purgadas, mas porque, sem elas, artista e obra seriam outros.

Também devem ser mencionadas as opções estéticas e narrativas do filme, as quais o desvinculam dos modelos teleológicos de biografias, prestando-se mais à fruição estética do que propriamente à reconstituição de eventos históricos. Com isso, Andrei Rublev constitui um filme biográfico que passa ao largo dos usuais questionamentos acerca da fidelidade ao registro histórico. 
A despeito da aclamação crítica, a obra de Tarkovsky é demasiadamente densa e pouco convencional para revogar os paradigmas que regem a produção comercial de filmes biográficos - como Amadeus, de Miloš Forman (1984), por exemplo, que busca um inatingível ideal de equilíbrio entre representação da obra e representação do artista -, mas exerce grande influência sobre realizadores menos comprometidos com a popularização ou o retorno financeiro de seus filmes. Assim, Eclipse de uma Paixão, de 1995, conta a história de Rimbaud e Verlaine sem citar um único poema de Rimbaud - e apenas um de Verlaine, em tradução para o inglês. Não se trata mais de um sacrifício do artista em detrimento de sua obra, e sim da adoção da narrativa de sua vida como aquilo que realmente interessa ao cinema. Por sua vez, em seu filme de 1998 sobre a vida do pintor inglês Francis Bacon - Love is the devil: study for a portrait of Francis Bacon, não lançado comercialmente no Brasil -, John Maybury propõe um biopic que deliberadamente não mostra uma única tela de autoria do seu sujeito. A explicação mais prosaica seria de que o diretor se viu obrigado a configurar seu filme dessa maneira devido a problemas de direitos autorais; ao mesmo tempo, o resultado final parece desejar subverter a ideia do corpo sacrificado do artista, substituindo sua obra pelo calvário de seu corpo - estratégia semelhante à utilizada por Greenaway em Que viva Eisenstein!.

As liberdades tomadas por Tarkovsky com a representação do artista foram facilitadas tanto pela pouca informação histórica que se tem a respeito de Rublev e de seu percurso formativo quanto pela inexistência de representações visuais do artista medieval - uma tela em branco, que Tarkovsky logrou preencher com a imagem até então desconhecida do competente ator Anatoliy Solonitsyn. Greenaway, no entanto, não teve tais vantagens. Não bastasse o fato de Serguei Eisenstein ser um cultuado artista do recente século XX sobre o qual muito já se escreveu e debateu, existem inúmeros registros escritos, pictóricos, fotográficos e fílmicos que, muito mais do que nos dar uma exata noção da aparência física do diretor soviético, configuram um "performative bundle" cuja transposição para as telas demanda um trabalho adaptativo bem mais complexo do que a mera identificação do physique du rôle ideal.
A expressão performative bundle, cunhada por Nina Cornyetz (2007), em outro contexto, para abarcar a persona pública forjada pelo escritor japonês Mishima Yukio a partir de textos em diferentes linguagens, ilumina a complexa rede de sentidos criada em torno de quaisquer artistas que têm sua vida e imagem pessoais não apenas esquadrinhadas, mas amalgamadas à sua criação artística, fenômeno que, em maior ou menor grau, tem abarcado quase todas as "celebridades" desde a popularização da fotografia. Evidentemente, biografias (autorizadas ou não; escritas ou filmadas) constituem parte fundamental desse fenômeno. A interpretação da vida como arte, do biografado como auteur, é muitas vezes relacionada a um "trabalho queer, formal ou informal [...] que faz uso de material extratextual como uma maneira de 'autorizar' a decodificação ou leitura de certos códigos narrativos e estilísticos em filmes como sendo específicos de uma cultura [queer]" (DOTY, 2004, p.22). Isso fica evidente nas análises de filmes de Eisenstein que percebem sua idealização do corpo e da personalidade masculina como um eco de seu status de queer auteur.

\section{Intermidialidade e a "montagem ideogramática"}

Conforme apontado no levantamento feito por Custen (1992, p.179), quase 40\% dos biopics "clássicos" de seu corpus tinham por fonte textos inespecíficos. ${ }^{4}$ Desafiando a fronteira entre roteiros originais e adaptados, tais obras se aproximam dos filmes "baseados em fatos reais", os quais, segundo Thomas Leitch (2007), têm sua força representacional aumentada - e não diminuída - justamente pelo fato de adaptarem textos sem autores, editores ou revisores, tirados de uma espécie de "livro da vida" tacitamente acolhido pelo público, a despeito do desconhecimento geral quanto às suas origens e finalidades.

O "livro da vida" tem, no entanto, diferentes suportes e contextos tecnológicos, que podem ser agenciados pelo cinema de maneira bastante específica. $\mathrm{O}$ filme biográfico exerce um profundo rearranjo dos textos originais, não raro se sobrepondo a eles para criar aquilo que Alison Landsberg (2004, p.25-26) denomina "memórias protéticas", imagens que circulam livremen- 
te nos meios de comunicação de massa e que, mesmo não tendo sustentação orgânica, tornam-se parte do arquivo pessoal de lembranças dos indivíduos. São essas próteses de memórias que nos permitem experimentar como recordações próprias eventos históricos não presenciados, como os ataques às Torres Gêmeas ou a chegada do homem à Lua.

Valendo-se das mesmas matérias-primas e tecnologias com que tais memórias são criadas e postas em circulação, filmes históricos e biográficos criam, deliberadamente ou não, registros do passado que, se não contrapostos por outras representações, facilmente se cristalizam como a "verdade". Assim, por exemplo, Oliver Stone cria, em JFK: a pergunta que não quer calar (1991), um continuum de imagens de arquivo (o rolo de Zapruder, as filmagens da autópsia de Kennedy, etc.) misturadas a reencenações dos mesmos momentos com atores que é facilmente aceito como um amálgama de elementos pertencentes a um mesmo regime de verdade - o filme/ficção se torna tecnicamente indistinguível das filmagens/realidade. Paradoxalmente, é a própria heterogeneidade das imagens combinadas (granulação do filme antigo, mistura de cenas coloridas e em preto e branco, câmara tremida, iluminação naturalista e "descuidada", ruídos acrescentados à trilha sonora, montagem frenética e não linear, etc.) que confere ao conjunto de enquadramentos uma homogeneidade quanto ao seu status de documento histórico.

Em contraposição a esse uso, Greenaway obtém de sua mistura de mídias uma estranheza que cria um distanciamento crítico no espectador. Embora tenha buscado em Elmer Bäck, o ator finlandês que representa Eisenstein, a semelhança física que permite o reconhecimento, Greenaway se encarrega de relativizá-la. Por exemplo, a primeira cena de Que viva Eisenstein! faz uso de uma mistura heterogênea de mídias de composição bastante semelhante à de $J F K$, combinando imagens de arquivo (fotos de época, cenas de filmes de Eisenstein, etc.) a filmagens com atores feitas no lugar mesmo onde se passou a história narrada (Guanajuato, no México), reencenações das fotos de época usando os atores do filme, e a música de Serguei Prokofiev. ${ }^{5}$ No entanto, ao contrário do que faz Oliver Stone em seu filme, Greenaway combina esses elementos de maneira a quebrar a ilusão de homogeneidade informativa. Assim, ao chegar ao hotel onde vai ficar hospedado durante as filmagens, Eisenstein é recepcionado por Frida Kahlo e Diego Rivera. Os atores que representam as três figuras históricas têm seus rostos justapostos a fotografias de época representando os "verdadeiros" Serguei, Frida e Diego, enfatizando o caráter ficcional das personagens que eles encarnam. Trata-se de um jogo de pular fronteiras entre fato e ficção marcadamente pós-modernista, e exemplar daquilo que Linda Hutcheon classifica como "metaficção historiográfica", textos "intensamente autorreflexivos e que, paradoxalmente, apropriam-se de eventos e personagens históricos" (1988, p.5).

Peter Greenaway é frequentemente descrito como sendo um cineasta "pós-moderno", ou "pós-estruturalista”. Willoquet-Maricondi e Alemany-Galway (2008, p.xiii) citam o próprio diretor, o qual, mesmo desconfiando do rótulo acadêmico, admite que, sendo "uma criatura de sua época", pode ser considerado como um autor do período pós-moderno. A pós-modernidade de Greenaway seria "uma desconstrução crítica de ideologias". Por trás de "todo o trabalho de Greenaway há um senso de pós-modernidade, de que as estruturas narrativas de sucessão cronológica e de causa e efeito são falsas, diante da natureza essencialmente caótica e problemática da experiência subjetiva, e de que os padrões que discernimos na experiência são totalmente ilusórios" (p.xiv-xv). Além disso, segundo essas autoras, a estética de Greenaway estaria informada pela teoria pós-estruturalista - em especial, pela obra teórica de Michel Foucault e de Jacques Derrida, às quais se somariam a reflexão sobre "um corpus de códigos ou mitos (como em Barthes)" e sobre "uma coleção de soluções imaginárias para contradições reais (como em Claude Lévi-Strauss)" (p.xiv).

Como ressalta Gerbase (2007), o pós-modernismo de Greenaway tem origens nas estéticas da vanguarda (modernista) dos anos $1920 .{ }^{6}$ A teoria da montagem ideogramática de Eisenstein tem eco no uso que Greenaway faz da técnica do picture in picture, ${ }^{7}$ por exemplo. Gerbase detecta em Eisenstein as mesmas estratégias de montagem que fazem com que a imagem de Greenaway se ofereça 'como um 'texto' para ser decifrado ou 'lido' pelo espectador"; trata-se de "usar as técnicas de fusão 
[...], sobreposição [...] ou divisão do quadro, que mostra múltiplas imagens opacas ao mesmo tempo" (GERBASE, 2007, p.10).

Nos filmes de Greenaway encontramos, muitas vezes, esquemas visuais de ideias ou conceitos abstratos, e é dessa maneira que podemos interpretar a concepção de ideograma que Greenaway herdou da teoria do cinema de Eisenstein. O uso de imagens sobrepostas, do efeito picture in picture, a narrativa não linear, o descompasso entre som e imagem, etc., são aplicações daquilo que Eisenstein defendia ao afirmar que a composição ou enquadramento de uma cena ou tomada devem ser consideradas como "um caso, por assim dizer, molecular de montagem" (EISENSTEIN, 1977, p.179). Eisenstein afirma que o princípio de montagem por superposição de elementos e atrito entre imagem e som é "ideogramático", pois teria origem na maneira como o ideograma (chinês) se articula:

Mas, isto é... montagem! [...] Sim, é exatamente isto que fazemos no cinema, combinando tomadas que pintam, de significado singelo e conteúdo neutro - para formar contextos e séries intelectuais. [...] Como o ideograma fornece um meio para a impressão lacônica de um conceito abstrato, esse mesmo método, quando transposto para uma exposição literária, dá origem a um laconismo idêntico, de agudez imagética. [...] Aplicado à colisão de uma sóbria combinação de símbolos, o método tem como resultado uma enxuta definição de conceitos abstratos. (EISENSTEIN, 1977, p.168)

Em seus filmes, Greenaway utiliza recorte e combinação, em um mesmo frame, de imagens analógicas e digitais, estáticas e em movimento, e obtidas a partir de diferentes suportes materiais - livros, papéis, texto em tipografia digital, película de cinema, imagem eletrônica, fotografia, fotocópia, animação tradicional, animação digital, e outros. O resultado é uma imagem compósita, "neobarroca", abundante, vertiginosa. Nas palavras de Greenaway, "podemos implementar as noções de multiplicidade de telas e de uma não cronologia temporal com a ajuda das novas tecnologias" (GREENAWAY em entrevista a MOURÃO, 2004, p.182-183).
A noção da multiplicidade de telas deveria estar no centro de nosso interesse cinematográfico. [...] Você pode experimentar as mais variadas noções de tempo, e pode mostrar o passado, o presente e o futuro, tudo em um mesmo plano. Você pode [...] mostrar três ângulos de um mesmo objeto, como em uma pintura de Braque ou Picasso. (GREENAWAY em entrevista a MOURÃO, 2004, p.184)

A noção de intermidialidade ${ }^{8}$ se aplica de forma orgânica ao trabalho de Peter Greenaway. De fato, ele é pintor de formação, atuou como produtor de documentários para a TV, tem uma presença considerável no circuito de exposições em museus e galerias de arte, criou espetáculos teatrais, escreve seus próprios roteiros e possui uma abordagem ao filmar que faz uso de várias outras mídias e expressões artísticas híbridas - não esquecendo, claro, que o cinema é, por definição, uma arte intermídia, ou, como propõe Spielmann (2001, p.55), uma "hipermídia".

Portanto, há o dado biográfico de que o artista Greenaway trabalha com diversas mídias; o imperativo formal de o cinema ser um "artefato humano" com "participação de mais de uma mídia" (WOLF, 2011, p.23); e o fato empírico de que, em seus filmes, o autor Greenaway faz uso de combinações de mídias. Assim, por exemplo, em The Draughtsman's Contract (1982), um importante componente da trama são desenhos, executados pelo personagem principal, de elementos arquitetônicos e paisagísticos. Em O Cozinheiro, o Ladrão, sua Mulher e o Amante (1989), os quadros de mestres flamengos que decoram as paredes do restaurante são um comentário à trama e às relações de poder estabelecidas entre as personagens. Em Que viva Eisenstein!, esse uso híbrido de imagens e elementos é posto em diálogo com a própria obra cinematográfica e pictórica do biografado, evidenciando não apenas a centralidade da pesquisa formal na obra de Eisenstein, como também o importante papel que essas inovações tiveram na criação do "estilo Greenaway".

A carreira do diretor britânico tem, inclusive, uma intersecção importante com o histórico mesmo da elaboração do conceito teórico de intermidialidade. Quando o uso de meios digitais de edição de imagem se tornou mais sofisticado, nos anos 1990, Greenaway 
foi um dos primeiros auteurs a se interessar pelos usos que podiam ser feitos dessas ferramentas no contexto do "cinema de arte". Ao mesmo tempo, a academia buscava, nesse momento, redefinir a relação entre mídias a partir de novos modelos artísticos. Assim, Yvonne Spielmann, por exemplo, propõe uma definição de intermidialidade que se baseia inicialmente na análise de A Última Tempestade:

No domínio do cinema, um estado intermidial ocorre quando os processos fílmicos de criação da imagem temporal são usados combinadamente com ferramentas digitais (como a paint box gráfica) e elementos de hipermídia (multidimensionais e omnidirecionais, ou seja, com múltiplas camadas). [...] Pode-se ver essa transição, por exemplo, no filme eletrônico de Peter Greenaway, A Última Tempestade (1991), que faz uso conjunto e misturado de mídia analógica e digital, obtendo um resultado que pode ser categorizado, no contexto do uso de mídia nas artes, como sendo intermídia, com elementos de imagens de diferentes mídias combinadas e transformadas para criar uma nova forma de imagem. (SPIELMANN, 2001, p.55)

Ainda que só 25 anos se tenham passado desde o lançamento de A Última Tempestade, a definição de Spielmann para intermídia parece, a um tempo, muito antiquada e um pouco óbvia demais. De fato, as últimas três décadas se encarregaram de banalizar completamente o uso combinado ou amalgamado de imagens digitais e analógicas, a ponto de ser essa hoje a norma, e não a exceção, no domínio da produção audiovisual. Por outro lado, se essa definição acadêmica de intermidialidade necessita ser revista, o seu uso em A Última Tempestade continua sendo considerado como pioneiro, pois até aquele momento na história do cinema, o uso de tecnologia de edição de imagem era algo restrito a gêneros "menores", como a ficção científica, e as imagens digitais eram consideradas meramente como um tipo de "efeito especial".

No caso específico de Que viva Eisenstein!, a intermidialidade manifesta-se de forma mais evidente tanto no uso combinado de imagens digitais e analógicas quanto na incorporação da fotografia como recurso composicional. Ainda que isso não constitua um desvio ou acréscimo à poética de Greenaway, aqui tais recursos se revestem de novos sentidos e inauguram complexos desdobramentos, uma vez que algumas cenas incorporadas à narrativa são de autoria de Eisenstein, não de Greenaway. Valendo-se do apagamento de fronteiras caraterístico dos biopics, Greenaway utiliza a obra ficcional de seu biografado como registro histórico, elevando o nível de complexidade tanto das questões relativas à representação e à ficcionalização da história quanto da noção de autoria em um filme acerca do (não) fazer fílmico.

\section{Considerações finais}

A obra de Greenaway apresenta de forma ficcional a explicação plausível e coerente proposta por Masha Salazkina (2007) para a "virada epistemológica" que David Bordwell (1974/1975) primeiramente identificou entre as obras e o pensamento de Eisenstein pré- e pós- México. Certamente, a adesão à tese da liberação sexual como fator de transformação pessoal e estética oferece algumas armadilhas, a primeira sendo a já referida erotização do latino. Entretanto, há que se admitir que esse estereótipo não é nem recente, nem restrito à visão dos europeus do Oeste, podendo ter influenciado a maneira com que Eisenstein, um homossexual vivendo sob um regime que oprimia sua condição, antevia sua viagem àquela terra exótica, talvez até mesmo predispondo-o às experiências que sua correspondência sugere terem ocorrido.

A segunda armadilha reside na representação do protagonista como emocionalmente imaturo, ingênuo e virgem aos 33 anos. De fato, Eisenstein só se casou com sua secretária, Pera Atasheva, em 1934, dois anos após o retorno do México e um ano após Stalin criminalizar a homossexualidade, o que reforça a tese de um casamento de fachada que só se fez necessário após a experiência mexicana. Entretanto, uma tal representação não se coaduna com o rico subtexto queer (notadamente o homoerotismo velado e a inexistência de papeis femininos) identificado nos filmes da fase formalista do cineasta. A imaturidade do Eisenstein ficcional também não parece condizente com a comprovada e incensada inteligência do personagem histórico, não apenas um poliglota detentor de profundos e diversi- 
ficados conhecimentos, mas também um comunista astuto o suficiente para perceber os descaminhos da revolução que apoiara, algo que hábil e corajosamente viria a criticar em seus filmes da segunda fase - em especial, em Ivan, o Terrível. Porém, é preciso lembrar, mais uma vez, que se trata de uma obra de Greenaway, e, se um certo sacrifício do realismo é o preço a se pagar por uma visão efetivamente inovadora e reveladora de um dos mais influentes artistas do século XX, parece que temos um bom negócio.

Que Viva Eisenstein! é coerente com a carreira autoral de Greenaway e, como tal, se apropria de textos de outros artistas para recriá-los intermidiaticamente. Ao mesmo tempo, a obra inova ao englobar, também, o discurso histórico, a imagem pública criada pelo e para o artista retratado, bem como traços estilísticos que o consagraram, paradoxalmente celebrando e apagando marcas autorais, exaltando e enfatizando a influência, em vez de temê-la ou dissimulá-la, como se almejasse ser a autobiografia que o irreverente esteta Serguei Eisenstein gostaria de ter feito. Com isso, Greenaway aventura-se em um dos mais populares e formulaicos gêneros cinematográficos, o biopic, conformando-se às tendências atuais de revisionismo histórico e de recuperação de vozes minoritárias. Entretanto, a fim de garantir a justa e coerente homenagem a Eisenstein, Greenaway aproxima-se dos filmes biográficos "de arte", conferindo ao seu biografado não apenas um tratamento esteticamente sofisticado, mas um retrato complexo da obra e da psicologia do artista, a exemplo do Andrei Rublev de Tarkovsky. Ao fazê-lo, Que Viva Eisenstein! demonstra que mesmo um dos mais influentes e prolíficos intelectuais do recente século $\mathrm{XX}$, a quem tanto "espaço" foi dado, resta incompreendido em alguns de seus traços mais elementares.

\section{Notas}

1. Título anteriormente utilizado por John Reed em seu relato da Revolução Bolchevique (REED, 1919).

2. Além das associações culturais e culinárias, a expressão olive skin, em inglês, quer dizer "pele morena".

3. Custen faz a distinção entre artists (49 produções) e entertainers (55 produções), em um universo de 291 filmes.
4. Em um universo de cem biopics, dez foram "sugeridos pela vida ou por obras do biografado", sete eram baseados em "reminiscências de parentes" e 21 não informavam qualquer fonte específica.

5. A "Marcha dos Cavaleiros", $1^{\circ}$. ato, cena 2 do balé Romeu e Julieta (1935, op.64). Prokofiev é autor da trilha sonora de Alexandre Nevsky (1938). A escolha da "Marcha dos Cavaleiros", talvez a composição mais conhecida de Prokofiev, pode parecer inicialmente gratuita, mas a expressividade musical da marcha tem relação com a arrogância do personagem Eisenstein que essa primeira cena pretende destacar, ao mostrá-lo chegando ao hotel, dando ordens, rodeado de pessoas que o acompanham com uma atitude servil.

6. Greenaway organizou, com sua esposa Saskia Boddeke, uma exposição sobre as vanguardas russas (The Golden Age of the Russian Avant-Garde, Moscou, Manege, 2014). Que a vanguarda seja referida, no título de uma exposição, como possuindo uma "época de ouro" (ou seja, tenha se tornado um "clássico") é uma das maneiras que Greenaway encontra para se afastar do modernismo, sem negar seu impacto: de maneira pós-moderna, ele revisita as vanguardas do início do século XX como uma tradição artística dentre outras da história da cultura, podendo tanto ser citada, como parodiada, ou ainda transformada em assunto de exposição em um museu. Cf. GOLDEN (2014).

7. Greenaway (em entrevista a MOURÃO, 2004, p.184) se refere a uma "multiplicidade de telas" ou framed vignette (GREENAWAY, 1998, p.32), uma expressão da pintura.

8. "Mídia', tal como o termo é usado em estudos literários e de intermidialidade, é um meio de comunicação com características próprias, definidas por convenção ou culturalmente, especificadas não apenas em virtude das propriedades técnicas ou institucionais do conduto (ou condutos), mas antes de tudo pelo uso de um ou mais sistemas semióticos na transmissão de um conteúdo, o que inclui (mas não se restringe a) mensagens referenciais. Em geral, a mídia faz diferença na determinação de que tipo de conteúdo pode ser evocado, como esse conteúdo é apresentado, e como ele é recebido" (WOLF, 2011, p.2). Intermidialidade stricto sensu é a "participação de mais de uma mídia em um artefato humano" (p.2-3). Intermidialidade lato sensu é "qualquer transgressão de limites entre mídias distintas por convenção, incluindo relações intra e extracomposicionais entre diferentes mídias [...] que vão desde uma perspectiva mais sincrônica em referência a artefatos individuais [...], mas designando também, a partir de uma perspectiva diacrônica e mídio-histórica, [...] a 'remidiação"' (p.3). 


\section{Referências}

ABELE, R. 'Eisenstein in Guanajuato' review: Peter Greenaway's homoerotic take on Russian filmmaker's Mexican Odyssey. The Wrap. 4 Feb. 2016. Disponível em: $\quad<$ http://www.thewrap.com/eisenstein-inguanajuato-review-peter-greenaway-sergeieisenstein-luis-alberti/>. Acesso em: 11 jul. 2016.

ALEXANDRE. (Título original: Alexander). Direção de Oliver Stone. 2004. 1 filme (175min), son., color.

ALEXANDRE Nevsky. (Título original: Aleksándr Névskiy). Direção de Serguei Eisenstein e Dmitri Vasilyev. 1938. 1 filme (111min), son., P\&B.

AMADEUS. Direção de Miloš Forman. 1984. 1 filme (180min), son., color.

AMANTES de Montparnasse, Os. (Título original: Les amants de Montparnasse). Direção de Jacques Becker. 1958. 1 filme (108min), son., P\&B.

ANDREI Rublev. (Título original: Andrey Rublyov). Direção de Andrei Tarkovsky. 1966. 1 filme (205min), son., color.

APÓS 3 anos, Justiça libera biografia que retrata Lampião gay. Folha de São Paulo, 4 out. 2014. Disponível em: <http://www1.folha.uol.com.br/ ilustrada/2014/10/1526620-apos-3-anos-justicalibera-biografia-que-retrata-lampiao-gay.shtml>. Acesso em: 9 jul. 2016.

BINGHAM, D. Whose lives are they anyway?: the biopic as contemporary film genre. New Brunswick / Londres: Rutgers University Press, 2010.

BORDWELL, D. Eisenstein's epistemological shift. Screen, v.15, n.4, 1974/1975, p.29-46.

CANÇÃO Inesquecível. (Título original: Night and Day). Direção de Michael Curtiz. 1946. 1 filme (128min), son., color.

CODELL, J. Gender, genius, and abjection in artist biopics. In: BROWN, T.; VIDAL, B. (Eds). The Biopic in Contemporary Film Culture. Nova Iorque: Routledge, 2014, p.160-173.

CORLISS, R. The Pleasures and Perils of Biopics True-Life dramas: must be Oscar time. Time, v.185, i.2, 26 Jan. 2015, p.60-61. Disponível em: <http://web.a.ebscohost. com.access.library.miami.edu/ehost/pdfviewer/ pdfviewer?sid=424f7dc5-2a56-4b1e-863e-f937e2c72 $24 \mathrm{~d} \% 40$ sessionmgr4004\&vid $=1 \&$ hid $=4214>$. Acesso em: 17 jun. 2016.

CORNYETZ, N. The Ethics of Aesthetics in Japanese Cinema and Literature: Polygraphic desire. Londres/ Nova Iorque: Routledge, 2007.

COZINHEIRO, o Ladrão, sua Mulher e o Amante, O.
(Título original: The Cook, the Thief, his Wife and her Lover). Direção de Peter Greenaway. 1989. 1 filme (120min), son., color.

CUSTEN, G. Bio/Pics: How Hollywood Constructed Public History. New Brunswick: Rutgers University Press, 1992.

DE-LOVELY. Direção de Irwin Winkler. 2004. 1 filme (125min), son., color.

DOTY, A. Whose text is it anyway? Queer cultures, queer auteurs and queer authorship. In: BENSHOFF, H.; GRIFFIN, S. Queer cinema, the film reader. Nova Iorque: Routledge, 2004, p.19-34.

DRAUGHTSMAN'S Contract, The (filme não lançado comercialmente no Brasil). Direção de Peter Greenaway. 1982. 1 filme (103min), son., color.

ECLIPSE de uma Paixão. (Título original: Total Eclipse). Direção de Agnieszka Holland. 1996. 1 filme (111min), son., color.

EISENSTEIN explored: Greenaway's biopic a look into a personal life. Russian Life, notebook. Mar./Apr., 2015, p.10.

EISENSTEIN, S. O princípio cinematográfico e o ideograma. In: CAMPOS, H. (Org.). Ideograma: lógica, poesia, linguagem. Traduções de Heloysa Dantas. São Paulo: Cultrix, 1977. p.163-185.

ENCOURAÇADO Potemkin. (Título original: Bronenosets Patyomkin). Direção de Serguei Eisenstein. 1925. 1 filme (75min), mudo, P\&B.

GERBASE, C. As raízes modernistas de Peter Greenaway. Sessões do Imaginário, v.X, p.8-12, 2007.

GOLDEN Age of the Russian Avant Garde by Saskia Boddeke \& Peter Greenaway, The. Luperpedia Foundation. Disponível em: <http://www. luperpediafoundation.com/the-golden-age-of-therussian-avant-garde/>. Acesso em: 9 jul. 2016.

GREEK lawyers halt Alexander case. BBC News, 3 Dec. 2004. Disponível em: <http://news.bbc.co.uk/2/hi/ entertainment/4064727.stm>. Acesso em: 9 jul. 2016.

GREENAWAY, P. Eisenstein in Guanajuato: 10 days that shook Eisenstein. Roteiro do filme. Paris: Dis Voir, 2014.

GREENAWAY, P. The Pillow Book. Roteiro do filme. Paris: Dis Voir, 1998.

GREVE, A. (Título original: Stachka). Direção de Serguei Eisenstein. 1925. 1 filme (82min), mudo, P\&B.

HOBERMAN, J. Alexander Nevsky. Criterion Collection Current, 23 Apr. 2001. Disponível em: <https://www. criterion.com/current/posts/8-alexander-nevsky>. Acesso em: 17 jun. 2016. 
HUTCHEON, L. A Poetics of Postmodernism. Nova Iorque: Routledge, 1988.

INFÂNCIA de Gorki, A. (Título original: Detstvo Gorkogo). Direção de Mark Donskoy. 1938. 1 filme (98min), son., P\&B.

IVAN, o Terrível. (Título original: Ivan Grozniy). Direção de Serguei Eisenstein. 1944 (Parte 1); 1958 (Parte 2). 1 filme (Parte 1: 99min; Parte 2: $88 \mathrm{~min}$; total: $187 \mathrm{~min}$ ), son., $\mathrm{P} \& \mathrm{~B}$.

JFK: a pergunta que não quer calar. (Título original: JFK). Direção de Oliver Stone. 1991. 1 filme (189min), son., color.

LANDSBERG, A. Prosthetic Memory: the transformation of American remembrance in the age of mass culture. Nova Iorque: Columbia University Press, 2004.

LEITCH, T. Based on a True Story. In: LEITCH, T. (Org.). Film Adaptation and Its Discontents: from Gone with the Wind to The Passion of the Christ. Baltimore: Johns Hopkins University, 2007. p.280-303.

LOVE is the devil: study for a portrait of Francis Bacon (filme não lançado comercialmente no Brasil). Direção de John Maybury. 1998. 1 filme (91min), son., color.

LOWENTHAL, L. Biographies in Popular Magazines. In: PETERS, J. D.; SIMONSON, P. Mass Communication and American Social Thought: key texts, 1919-1968. Lanham: Rowman and Littlefield, 2004. p.188-205.

MISHIMA: uma vida em quatro capítulos. (Título original: Mishima: a life in four chapters). Direção de Paul Schrader. 1985. 1 filme (121min), son., color.

MOURÃO, M. Cinema e Novas Tecnologias: conversa com Peter Greenaway. In: MACIEL, M. (Org.). O cinema enciclopédico de Peter Greenaway. São Paulo: UNIMARCO, 2004. p.179-190.

O'SUlLIVAN, M. 'Eisenstein in Guanajuato': Russian filmmaker finds love in the New World. The Washington Post. 3 Mar. 2016. Disponível em: <https:// www.washingtonpost.com/goingoutguide/movies/ eisenstein-in-guanajuato-russian-filmmaker-findslove-in-the-new-world/2016/03/03/287d83b4-df3311e5-846c-10191d1fc4ec_story.html>. Acesso em: 17 jun. 2016.

OUTUBRO: dez dias que abalaram o mundo. (Título original: Oktyabr': Desyat' dney kotorye potryasli mir). Direção de Grigori Aleksandrov e Serguei Eisenstein. 1928. 1 filme (104min), son., P\&B.

PIDDUCK, J. Contemporary costume film: space, place and the past. Londres: British Film Institute, 2004.

QUE VIVA EISENSTEIN! (Título original: Eisenstein in Guanajuato). Direção de Peter Greenaway. 2016. 1 filme (105min), son., color.
QUE VIVA MÉXICO! (Título original: ¡Que viva México!). Direção de Serguei Eisenstein. 1979 (lançamento póstumo). 1 filme (90min), son., P\&B.

REED, J. Ten days that shook the world. Nova Iorque: Boni and Liveright, 1919.

REMBRANDT. Direção de Alexander Korda. 1937. 1 filme (85min), son., P\&B.

ROSE, S. Andrei Rublev: the best arthouse film of all time. The Guardian. 20 out 2010. Disponível em: <https:// www.theguardian.com/film/2010/oct/20/andreirublev-tarkovsky-arthouse>. Acesso em: 28 maio 2016.

RUSSIA passes law banning gay 'propaganda'. The Guardian, 11 Jun. 2013. Disponível em: <https://www. theguardian.com/world/2013/jun/11/russia-lawbanning-gay-propaganda>. Acesso em: 12 jul. 2016.

SALAZKINA, M. Addressing the dialectics of sexual difference in Eisenstein's 'Que viva México!'. Screen, v.48, n.1, Spring 2007, p.45-67.

SALAZKINA, M. In Excess: Sergei Eisenstein's Mexico. Chicago: University of Chicago Press, 2009.

SPIELMANN, Y. Intermedia in Electronic Images. Leonardo, 2001, v.34, n.1, Feb. 2001, p.55-61.

ÚlTIMA Tempestade, A. (Título original: Prospero's Books). Direção de Peter Greenaway. 1991. 1 filme (123min), son., color.

ÚLTIMO Tango em Paris, O. (Título original: Ultimo Tango a Parigi). Direção de Bernardo Bertolucci. 1972. 1 filme (129min), son., color.

VIDAL, B. Feminist historiographies and the woman artist's biopic. Screen, v.48, n.1, Spring 2007, p. 70-90.

WAUGH, T. A fag-spotter's guide to Eisenstein. The Body Politics: gay liberation journal, Jul/Aug 1977, p. 15-17.

WHITE, H. Historiography and Historiophoty. The American Historical Review, v.93, n.5, 1988, p.11931199.

WILLOQUET-MARICONDI, P.; ALEMANY-GALWAY, M. Introduction: a Postmodern/Poststructuralist Cinema. In: WILLOQUET-MARICONDI, P.; ALEMANY-GALWAY, M. (Orgs.). Peter Greenaway's Postmodern/Poststructuralist Cinema. Plymouth: Scarecrow, 2008. p.xiii-xxxv.

WOLF, W. (Inter)mediality and the Study of Literature. CLCWeb: Comparative Literature and Culture. 2011, v.13, n.3, p.1-10. Disponível em: <http://dx.doi. org/10.7771/1481-4374.1789>. Acesso em: 23 jun. 2015 .

Recebido em: 12/07/2016 Aceito em: 03/09/2016 